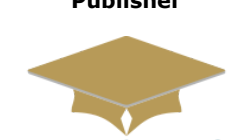

MEDRESEARCH

www.medresearch.in

\title{
Role of drug de-addiction centers to control the drug addiction in the state of Punjab
}

\author{
Singh G. ${ }^{1}$, Mitra Y. ${ }^{2 *}$, Sidhu B. ${ }^{3}$, Kaur P. ${ }^{4}$ \\ DOI: https://doi.org/10.17511/ijphr.2019.i2.07
}

\footnotetext{
${ }^{1}$ Gumreet Singh, Professor, Department of Community Medicine, Punjab Institute of Medical Sciences, Jalandhar, Punjab, India.

2* Yash Mitra, Assistant Professor, Department of Community Medicine, Punjab Institute of Medical Sciences, Jalandhar, Punjab, India.

3 B.S Sidhu, Professor and Head, Department of Psychiatry, Government Medical College, Patiala, Punjab, India.

4 Paramjeet Kaur, Professor and Head, Department of Community Medicine, Government Medical College, Patiala, Punjab, India.
}

Introduction: The abuse of intoxicants in one form or the other has lived with the mankind as part of the life for ages. Alcohol, opium and cannabis were the traditional substance of abuse in India marked by moderate consumption generally ritualized in social gatherings. The problem of drug abuse acquired new and alarming dimensions with the introduction of heroin and other new forms of drugs in late seventies and early eighties. The commonly used substances in the world are nicotine and alcohol (most commonly), opium, codeine, cocaine, caffeine, barbiturates, more than 13 million Americans use illegal drugs. According to a survey, $80 \%$ of Punjabi youth takes drugs. Material and Methods: The evaluation of 10 Drug De-Addiction Centers (DDC) was done to study the role of these centers to control the menace of drug addiction in the state of Punjab. The data regarding profile of patients, satisfaction with services and behavior of staff of centers was collected from those patients admitted in the respective centers during the time of study and statistically evaluated. The study was carried out during April 2009 to March 2010. Results: Centers under the administrative control of Indian Red Cross Society, out of 90 patients, 10 (11.1\%), $40(44.4 \%)$ and $40(44.4 \%)$ patients had opinion that staff behavior and staff services were good, average and poor respectively. As per medical services were concerned, $10(11.1 \%), 45(50 \%)$ and $35(38.9 \%)$ patients said it is good, average and poor respectively. Similarly $27(30 \%)$ said that there was harassment by staff personnel at times and $63(70 \%)$ denied any such incident at centers run by Indian Red Cross Society. Conclusion: There is a strong need to expand the scope of research in future regarding the field of drug de-addiction to improve the effectiveness of treatment by the DDC centers providing preventive and curative services to the addicts.

Keywords: Abuse, Alcohol, Opium, Consumption, Social, Million

Corresponding Author

Yash Mitra, Assistant Professor, Department of Community Medicine, Punjab Institute of Medical Sciences, Jalandhar, Punjab, India.

Email: mitrayash@yahoo.com

\section{How to Cite this Article}

Singh G, Mitra Y, Sidhu BS, Kaur P. Role of drug deaddiction centers to control the drug addiction in the state of Punjab. Public Health Rev Int J Public Health Res. 2019;6(2):89-97.

Available From

https://publichealth.medresearch.in/index.php/ijphr/ article/view/105
To Browse

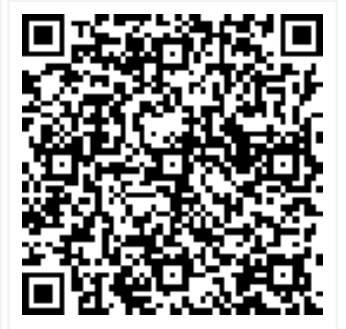

Manuscript Received 2019-02-04

Conflict of Interest No
Review Round 1 2019-02-10

Funding

Nil

Review Round 2
2019-02-16
Ethical Approval
Yes

Review Round 2

Yes
Review Round 3

Plagiarism X-checker $7 \%$
Accepted 2019-02-21

Note

(C) 2019 by Gumreet Singh, Yash Mitra, B.S Sidhu, Paramjeet Kaur and Published by Siddharth Health Research and Social Welfare Society. This is an Open Access article licensed under a Creative Commons Attribution 4.0 International License https://creativecommons.org/licenses/by/4.0/ unported [CC BY 4.0]. 


\section{Introduction}

Use of synthetic substances capable of having an altered effect on human health and behavior is of recent origin. Alcohol, opium and cannabis were the traditional substances of abuse in India marked by moderate consumption generally ritualized in social gatherings. The problem of drug abuse acquired new and alarming dimensions with the introduction of heroin and other new forms of drugs in late seventies and early eighties [1].

WHO (2002) estimated that there are about 2 billion people worldwide who consume alcoholic beverages [2]. The commonly used substances in the world are nicotine and alcohol (most commonly), opium, codeine, cocaine, caffeine, barbiturates (ainobarbital, pentobar-bital), benzodiazepines (valium, ativan, Xanax), hallucinogens: LSD, mescaline, cannabis, marijuana and hashish. More than 13 million Americans use illegal drugs, more than 2 million are known to abuse prescription drugs, 60 million are hooked on cigarettes, 33 million binge on alcohol, and 12 million are heavy drinkers [3].

India is hemmed between the golden triangle which include Myanmar (Burma), Laos, Vietnam, and Thailand and the golden crescent which include Afghanistan, Iran, and Pakistan; two prominent drug-producing hubs in the World. India as a natural transit zone, faces a major problem of drug trafficking.

Drug addiction in India has of late emerged as a matter of great concern both due to the social and economic burden caused by substance abuse. National Survey (2002), on extent, pattern and trend of drug abuse conducted at the behest of ministry of social justice and empowerment, government of India (MSJE) and United Nations indicates that about 15 million persons addicted to alcohol and various kinds of other drugs need urgent attention for their treatment, rehabilitation and reintegration into social mainstream [4].

In Punjab, drug addiction is a cancer which is crippling the mental and physical well being of the youth population of Punjab, rendering them lifeless. Focus-less, direction-less youth with lots of time and some money in hand get easy lured into the drug habit, either prompted by peers or on their own. It is allover the country, except that its affliction is quicker and deeper in Punjab, than other places. In short, easy money, nothing to be focused on,
Plenty of free time on hand, lack of proper parental supervision, have all contributed to the drug menace in Punjab [5].

According to a survey, $80 \%$ of Punjabi youth takes drugs and $78 \%$ people say that users make their first contact with drugs through friends (sikhgiving.com 2006). The problem is not restricted to youth alone. Children as young as 12 years old are found addicted. Males, aged 45 and above are found to be addicted to liquor.

This menace is catching up even with the females. In India laws against drugs are Narcotic Drugs and Psychotropic Substances (NDPS) act, 1985 (Gazette of India1985, 1989) and the Drugs and Cosmetics Act, 1940 (Gazette ofIndia 1940) [6].

Drug rehabilitation is an umbrella term for process of medical and psychotherapeutic treatment, for dependency on psychoactive substances such as alcohol, prescription drug, and so-called street drugs such as cocaine, heroin or amphetamines.

The obvious intent is to enable the patient to decrease their previous level of substance abuse, for the sake of avoiding its psychological, legal, social, and physical consequences. Drug rehabilitation is a multi-phased, multi-faceted, long term process.

Drug rehabilitation centers play an important role to make drug addict free of addiction. The treatmentcum-rehabilitation centers provide services to the community as awareness generation, Identification of addicts, motivational counseling, detoxification/ de-addiction, vocational rehabilitation, after care and re-integration into the social mainstream and preventive education.

There are different guidelines for treatment-cumrehabilitation centers according to their bed capacity (15-bedded, 30-bedded, 50-bedded, 60-bedded).

The guidelines are laid down by Ministry of Social Justice and empowerment, Government of India. The ministry runs a programme named as "Scheme for prevention of alcohol and substance (drugs) abuse" launched in 1985 [2].

The government of India would provide financial support to the organizations for institutionalized activities, stress would be on mobilization of community resources and greater community participation.

At present 123 such centers have been established across the country. The ministry of social justice and 
Empowerment under its scheme is assisting 373 NGO's for maintaining 401 De-addiction-cumrehabilitation centers and 68 counseling and awareness centers all over the country [7].

The drug-abuse is being given due attention by the government of Punjab and the state branch of Red Cross with its headquarters at Chandigarh is also putting its best efforts in fighting against the menace of drug addiction by running different drug De-addiction Centers.

These are functional at village Khanpur (Ropar), Patiala, Gurdaspur, Dahan Kaleran (Nawan Shahar) and counseling center at Chandigarh are under the control of Red Cross Chandigarh.

The centres at Bathinda, Ludhiana, Moga, Faridkot, Marisa, Amritsar and other places are being run under control of district branches of Red Cross Society. Some centers are also being run under private sector. The addicts are given free treatment, yoga therapy and counseling services to develop strong will power to resist the craving for drug abuse.

Family counseling services by qualified psychiatrists are provided to the addicts to enable them to overcome their addiction. This study was carried out to evaluate the role of drug De-addiction Centers running across various districts of Punjab to control the drug addiction in the state of Punjab.

\section{Objectives}

- To evaluate the satisfaction level of the patients regarding the services provided by the Drug Deaddiction Centres.

- To assess the health services to the patients provided by the Drug De-addiction Centres.

- To assess the role of Drug De-addiction Centres to control the drug addiction in the state of Punjab

\section{Material and Methods}

Setting andTypeofStudy: In this study a total of 10 drug De-addiction Centers (DDCs) situated across various districts of Punjab were randomly selected for evaluation. The evaluation of the Drug De-Addiction Centers (DDC) done to study the role of the centers to control the menace of drug addiction in the Punjab State.

The infrastructure, staff pattern, preventive, promotive, curative and rehabilitative services.
Patient's records available with drug de-addiction centers were evaluated. It is a Cross-Sectional Study and is carried out from April 2009 to March 2010.

Sampling Method: The information regarding profile of the patients admitted in the respective centres during the time of study was collected. After taking their informed consent, the data of their satisfaction with services and behavior of staff towards them was also obtained to assess the role of DDCs to control the drug addiction in the state of Punjab.

The study was done in ten drug De-addiction Centers across various districts of Punjab which included 7 DDCs run by Indian Red Cross Society (selected by random sampling out of a list of 15 centers) and 3 DDCs being run by private registered societies were included in the study as only permission of three was issued by the concerned authorities of the private drug de-addiction Centers.

Details of Center: Seven DDCS being run by Indian Red Cross Society which were selected for the study are:- Red Cross Drug De-Addiction Centre, Saket Hospital, Patiala; Integrated Rehabilitation Centre for Addicts, Kharar (Mohali); Red Cross Drug De-Addiction Centre, Nawan Shahar; Red Cross Drug De-Addiction Centre cumRehabilitation Centre, Gurdaspur; Drug De-Addiction Centre, DN Kotnis Health and Education Centre, Ludhiana; Red Cross Drug De-Addiction Centre cum-Rehabilitation Centre, Guru Gobind Singh Medical College and Hospital Complex, Faridkot; Drug De-Addiction Centre, Civil Hospital, Bathinda.

Three DDCs being run by private registered societies which were selected for the study are:Guru Nanak De-Addiction cum-Counseling Centre, Dasuya (Hoshiarpur); Parivartan De-Addiction cum Counseling Centre, Qadian (Gurdaspur); Ranjit DeAddiction Centre, Bhogra (Hoshiarpur).

Sampling Method: Interview technique was used to fill the pre-designed and pre-tested proformas.

Sample Collection: Project directors of all ten DDCS were interviewed and on the basis of a pretested proforma- I, data was collected from records present at respective centers for a period of April 2009 to 3lst March 2010 regarding the role of DDCs to control drug de-addiction in Punjab.

The data regarding the infrastructure, staff pattern, number of OPD and Indoor demographic profile of drug addicts like education status, marital status, 
Drugs abused, details of stay, treatment outcome, number of drop-outs, rehabilitation services, outreach services, additional treatment required, number of follow up visits details of staff personal trained in last two years was also obtained.

Interview of indoor patients who were admitted on the days of scheduled visits was done after obtaining their informed consent and explaining them the purpose of study. Confidentiality of information provided by them was ensured.

Data was obtained regarding their sociodemographic profile, details of drug abused, previous history of admission to any DDC, family history of any drug abuse, satisfaction regarding the services being provided, staff behavior and satisfaction with the Indoor stay facilities.

\section{Inclusion Criteria}

Proforma-I: Those centers were included which were functional for more than 12 months. Those patients who were admitted in the DDCs and physically available at the time of visit were included. A total of 120 patients were interviewed.

\section{Exclusion Criteria}

Proforma-II: Those patients who were in state of addiction or inebriated or not available due to any reason at time of visit were excluded i.e. 5 patients were excluded.

Ethical consideration and Permission: for the survey was obtained from the institutional Ethical committee to carry on the research. To conduct the study in DDCs the permission was obtained from the administrators of Indian Red Cross Society and from the Directors of Private Registered Societies running the private DDCs in Punjab.

Statistical Methods: The data thus collected was then analyzed to evaluate the role of drug Deaddiction Centers to control the drug-addiction in State of Punjab and relevant statistical tests like Chi-square test were applied. Level of significance was determined as its ' $P$ ' value with $p<0.05$ is considered as statistically significant and $p>0.05$ as non-significant.

\section{Results}

The findings of the study are as follows:

The various types of drugs abused are propoxyphene $(29.3 \%)$, alcohol $(14.8 \%)$ and bhukki $(13.3 \%)$ opium $(4.3 \%)$, cannabis or bhang $(2.4 \%)$,
Buprenorphine (1:9\%), brown sugar (I.6\%), volatile solvents $(1.3 \%)$ as inhalants, cocaine $(1.1 \%)$, heroin $(0.9 \%)$, morphine $(0.4 \%)$, hallucinogens $(0.2 \%)$. Other substance abused $(19.0 \%)$ were Iodex, petrol, boot polish, spirit, kerosene etc.

Table 1 depicts that total 120 patients were interviewed and 5 patients were excluded as per exclusion criteria. All were males. Mean age of patients was 31.22 years with majority of patients being in age group of $20-30$ years $(47.5 \%)$ followed by $30-40$ years $(35.8 \%)$.

Table II depicts that mean age for starting drug abuse was 21 years. $38.3 \%$ patients started drugs in age group of $20-25$ years and $26.7 \%$ in $15-20$ years. It shows that youth of Punjab is becoming victim of drug abuse at a very young age.

Table III shows that 19 (16\%) patients had positive family history of drug abuse.72 $(60.0 \%)$ patients were brought to centre by family members, 26 (22\%) reported themselves, 15 (12\%) were brought by relatives. 47 (39.2\%) patients had positive history of previous treatment at any other drug De-addiction Centers and positive history of relapse to drugs again after previous treatment.

Table 4 shows that at centers under the administrative control of Indian Red Cross Society, out of 90patients, $10(11.1 \%), 40(44.4 \%)$ and 40 $(44.4 \%)$ patients had opinion that staff behavior and staff services were good, average and poor respectively.

As per medical services were concerned, 10 $(11.1 \%), 45(50 \%)$ and $35(38.9 \%)$ patients said it as good, average and poor respectively. Similarly 10 $(11.1 \%), 50(55.6 \%)$ and $30(33.3 \%)$ patients said that counseling services were good, average and poor respectively. $27(30 \%)$ said that there was harassment by staff personnel at times and 63 (70\%) denied any such incident at centers run by Indian Red Cross Society.

Table 5 depicts that 37 (41.1\%) patients felt change in behavior and were determined to abstain from drug abuse in future and said that they will recommend the centre to others but 53 (58.9\%) denied it at centers run by Indian Red Cross Society.

Only $6(20 \%)$ patients felt change in behaviour and were determined to abstain from drug abuse in future and said that they will recommend the centre to others but $24(80 \%)$ denied it at centers run by private registered societies. 
Table 6 shows that $37(41.1 \%)$ patients were satisfied with Indoor stay facilities and 53 (58.9\%) were not satisfied at centers run by Indian Red Cross Society. At centers run by private registered societies, out of 30 patients $2(6.7 \%), 10(33.3 \%$ and $18(60 \%)$ had opinion that staff behavior and staff services were good, average and poor respectively.

As per medical services were concerned, 2 (6.7\%), $10(33.3 \%)$ and $18(60 \%)$ patients said it as good, average and poor respectively. Similarly $3(10 \%), 8$ $(26.7 \%)$ and $19(63.3 \%)$ patients said that counseling services were good, average and poor respectively.

Table 7 shows that $13(43.3 \%)$ said that there was harassment by staff personnel, and 17 (56.7\%) denied any such incidence at centres run by private registered societies. Table 8 shows that $24(80 \%)$ and $53(58.9 \%)$ patients were not satisfied with indoor stay facilities being provided at centres under the administrative control of private registered societies and Indian Red Cross Society respectively.

Table-1: Age, Sex, Residence, Marital Status wise Distribution of Patients undergoing Treatment at De-addiction Centers.

\begin{tabular}{|c|c|c|c|}
\hline & Particulars $(n=120)$ & $\begin{array}{l}\text { Number of } \\
\text { Patients }\end{array}$ & $(\%)$ \\
\hline \multirow[t]{10}{*}{ Age (Years) } & Male & 120 & 100 \\
\hline & Female & 0 & 0 \\
\hline & $10-20$ & 2 & 1.7 \\
\hline & $20-30$ & 57 & 47.5 \\
\hline & $30-40$ & 43 & 35.8 \\
\hline & $40-50$ & 10 & 8.4 \\
\hline & $50-60$ & 7 & 5.8 \\
\hline & $>60$ & 1 & 0.8 \\
\hline & Range & \multicolumn{2}{|c|}{$15-73$ years } \\
\hline & Mean \pm SD & \multicolumn{2}{|c|}{$31.22 \pm 9.50$ years } \\
\hline \multirow{3}{*}{$\begin{array}{l}\text { Marital } \\
\text { Status }\end{array}$} & Un-married & 38 & 31.7 \\
\hline & Married & 78 & 65.0 \\
\hline & $\begin{array}{l}\text { Separated / divorced due to drug } \\
\text { abuse }\end{array}$ & 4 & 3.3 \\
\hline \multirow[t]{2}{*}{ Residence } & Urban & 49 & 41.0 \\
\hline & Rural & 71 & 59.0 \\
\hline
\end{tabular}

Table-2: Age of starting drug abuse by patients undergoing treatment at De-addiction Centers

\begin{tabular}{|c|l|l|l|}
\hline \multicolumn{2}{|c|}{ Particulars $(\mathrm{n}=\mathbf{1 2 0})$} & Number of Patients & Percentage \\
\hline Age of Starting Drugs & $10-20$ & 42 & 35.0 \\
\cline { 2 - 4 } & $20-30$ & 65 & 54.2 \\
\cline { 2 - 4 } & $30-40$ & 11 & 9.1 \\
\hline
\end{tabular}

\begin{tabular}{|l|l|l|l|}
\hline $40-50$ & 2 & 1.7 \\
\cline { 2 - 4 } & $50-60$ & 0 & 0 \\
\cline { 2 - 4 } & $>60$ & 0 & 0 \\
\cline { 2 - 4 } & Range & \multicolumn{1}{|c|}{$13-48$ year } \\
\cline { 2 - 4 } & Mean \pm SD & $21.15 \pm 5.29$ year \\
\hline
\end{tabular}

Table-3: Family history of drug intake, previous history of DDC visit, History of relapse and persons brought to centre by whom at DDCs.

\begin{tabular}{|l|l|l|l|}
\hline \multicolumn{2}{|c|}{ Particulars ( $\mathbf{n}=120)$} & \multicolumn{1}{|c|}{$\begin{array}{c}\text { Number of } \\
\text { Patients }\end{array}$} & $(\%)$ \\
\hline Family History of Drug Intake & Yes & 19 & 16 \\
\cline { 2 - 4 } & No & 101 & 84 \\
\hline \multirow{3}{*}{ Person who brought patient to DDC } & Self & 26 & 22 \\
\cline { 2 - 4 } & Family & 72 & 60 \\
\cline { 2 - 4 } & Relative & 15 & 12 \\
\cline { 2 - 4 } & Others & 7 & 6 \\
\hline Previous History of DDC Visit and & Yes & 47 & 39.2 \\
\cline { 2 - 4 } History of Relapse & No & 73 & 60.8 \\
\hline
\end{tabular}

Table -4: Satisfaction of Patients from services being provided at De-addiction Centers

\begin{tabular}{|c|c|c|c|c|c|c|c|}
\hline$(n=120)$ & & ood & Ave & rage & & oor & Total \\
\hline DDC run by & IRCS & PRS & IRCS & PRS & IRCS & PRS & \\
\hline Staff Services & 10 & 2 & 40 & 10 & 40 & 18 & 120 \\
\hline Staff Behaviour & 10 & 2 & 40 & 10 & 40 & 18 & 120 \\
\hline Medical Services & 10 & 2 & 45 & 10 & 35 & 18 & 120 \\
\hline Counseling Services & 10 & 3 & 50 & 8 & 30 & 19 & 120 \\
\hline
\end{tabular}

(IRCS $=$ Centers run by Indian Red Cross Centre Society, PRS=Centers run by Private Registered Societies)

Table-5: Perception of Change in Behaviour Among- Self in Patients Undergoing Treatment at De-addiction Centers.

\begin{tabular}{|l|l|l|}
\hline & \multicolumn{2}{|c|}{ Feeling of Change in Behaviour at Centers run by } \\
\hline$(n=120)$ & Indian Red Cross Society & Private Registered Societies \\
\hline Yes & $37(41.1 \%)$ & $6(20 \%)$ \\
\hline No & $53(58.9 \%)$ & $24(80 \%)$ \\
\hline Total & 90 & 30 \\
\hline \multicolumn{3}{|c|}{ Chi square $: 4.36 ; p<0.05 ;$ Significant } \\
\hline
\end{tabular}

Table-6: Recommendation of Centre to Other People by Patients Undergoing Treatment at De-addiction Centers.

\begin{tabular}{|l|l|l|}
\hline & \multicolumn{2}{|c|}{ Recommendation of Centre to Others by Patients } \\
\hline$(n=120)$ & Indian Red Cross Society & Private Registered Societies \\
\hline Yes & $37(41.1 \%)$ & $6(20 \%)$ \\
\hline No & $53(58.9 \%)$ & $24(80 \%)$ \\
\hline Total & 90 & 30 \\
\hline \multicolumn{3}{|c|}{ Chi square $: 4.36 ; p<0.05 ;$ Significant } \\
\hline
\end{tabular}


Table-7: Incidents of Harassment by Staff at Centre as Told by Patients Undergoing Treatment at De-addiction Centers.

\begin{tabular}{|l|l|l|}
\hline & \multicolumn{2}{|c|}{ Harassment by Staff at Centers run by } \\
\hline$(n=120)$ & Indian Red Cross Society & Private Registered Societies \\
\hline Yes & $27(30 \%)$ & $13(43.3 \%)$ \\
\hline No & $63(70 \%)$ & $17(56.7 \%)$ \\
\hline Total & 90 & 30 \\
\hline \multicolumn{3}{|c|}{ Chi square $: 1.8 ; p>0.05 ;$ N.S. } \\
\hline
\end{tabular}

Table -8: Satisfaction of Patients from Indoor Say Facilities at De-addiction Centers

Satisfaction from Indoor Stay Facilities at Centers run by

\begin{tabular}{|l|l|l|}
\hline$(n=120)$ & Indian Red Cross Society & Private Registered Societies
\end{tabular}

\begin{tabular}{|l|l|l|}
\hline Yes & $37(41.1 \%)$ & $6(20 \%)$ \\
\hline No & $53(58.9 \%)$ & $24(80 \%)$ \\
\hline Total & 90 & 30 \\
\hline \multicolumn{2}{|c|}{ Chi square : $4.36 ; \mathrm{p}<0.05 ;$ Significant } \\
\hline
\end{tabular}

\section{Discussion}

The study was conducted in ten DDCs running in various districts of Punjab. Out of 10 DDCs, 7 were under the administrative control of Indian Red Cross Society and 3 were under the control of Private Registered Societies.

A pretested proforma-I was used to collect details regarding centre's Infrastructure and Human Resources' strength and health services provided by these centers.

A total of 120 patients were interviewed and information regarding their socio-demographic profile and their satisfaction with the services being provided and Indoor stay facilities at DDC was collected maintaining full confidentiality.

The outcome of the study shows that age group 2040 years is the most common age group in which drug-addicts are more. 71 (59\%) patients belonged to rural area and $49(41 \%)$ were from urban areas. $78(65.0 \%)$ patients were married followed by 38 (31.7\%) unmarried. $4(3.3 \%)$ were divorced due to drug abuse.

Similar findings were reported by Mohan et al (2002) who found that $59 \%$ belonged to $20-30$ years group and $25 \%$ to $30-40$ years group[8]. De Silva and Fonseka (2008) found that mean age of the drug addicts was $34.04+7.5$ years which is similar to mean age of $31.22+9.50$ years of present study [9].

Thus age group of 20- 40 years is the most common age group in which drug addicts are more. Singh et
Al (2006) found that $44.13 \%$ of the abusers had started substance abuse at the age of 16 to 20 years[10]. Educated youth is falling in the trap of drug abuse Which is in consistence with the findings of Singh et al. (2006) [10].

Out of 120 patients, for multiple drug abuse, 75 $(62.5 \%)$ were tobacco addict, $51(42.5 \%)$ patients were addicted to alcohol. Among opioids, 49 $(40.8 \%)$ were addicted to capsule, $19(15.8 \%)$ to smack,17 (14.1\%) were addicted to opium, 11 $(9.2 \%)$ to tablets and $7(5.8 \%)$ to bhukki.

Saluja et al (2007) found that mean age at 1st use of primary substance was 14.8 years [12].

Similar finding were reported by kadri et al (2003) who found that $26.1 \%$ had positive family history of drug addiction.Age of starting habit was earlier ( $<20$ years) in those who were having easy excess of availability of drugs [11].

The study shows that private as well as centers were less as compared to the demand load of drug addicts and even less patients were attending these centres due to the inhuman behavior of staff.

Even out of those patients, majority were not satisfied at these centers. Various reasons told by patients were like when they don't obey orders of staff members, they were being verbally or physically abused and tortured by DDC staff.

As far as medical services were concerned, at times it became irregular. Even during counseling sessions, at times derogatory remarks were made by the counselors. Which is against the guidelines of Government and also shattered the faith to get treated from private DDC's.

On statistical analysis with Chi-square test, it was found statistically significant that more patients were feeling a change in themselves at Red Cross Centers $(p<0.05)$. From this, we can know the impact of DDC on the patient behavior and less patients were showing positive response at private centers.

On statistical analysis with Chi-square test, it was found statistically that more patients were feeling a change in themselves at Red Cross centers $(p<0.5)$ and more patients are willing to recommend Red Cross Centers to other addicts for treatment.

Majority of the patients are not happy to be treated in private DDCs due to huge expenditures and wrong doings. It showed feelings of patients about 
The DDC and had direct association with services provided at DDCs at which they were getting treatment. Majority of patients at private DDCs were unhappy with the centers.

On statistical analysis with Chi-square test, no significant difference was found regarding incidences of harassment but at centers run by Private Registered Societies (PRS) there were incidences of harassment of patients like beating, slapping and keeping them without food.

On statistical analysis with Chi-square test it was found statistically significant that more patients were unsatisfied at DDCs run by Private Registered Societies $(p<0.05)$.

Possible reasons may be physical or verbal abuse, have to sleep on mattresses rather than on bed and longer duration of treatment period of six months or even more with huge expenditure of treatment in the private DDCs'

\section{Conclusion}

On evaluation of drug de addiction centers it was found that these centers are just running. There is urgent need for improvement in the services and facilities to patients at these centers run by Indian red Cross Society and private registered societies.

Therefore the recommen-dations regarding role of DDCs to control the drug addiction in the state of Punjab are as below:-

- Centers run by IRCS are charging Rs. 1400 per month and private registered societies Rs. 4000-5000 per month from the family of the drug addicts. It is strongly recommended that the treatment should be provided free of cost to the needy and poor patients.

- Physical and mental harassment of drug addicts must be stopped.

- Vacant posts of councilors and auxiliary staff must be filled.

- Centers run by private registered societies have severe staff shortage.

- Vocational rehabilitation services like tailoring, carpentry or computer courses must be provided and these centers be financed by the government.

- The project directors of these centers must be retired persons from the medical profession or from allied fields.
- Specialized training of the staff in de-addiction is urgently needed so that they can understand the needs and behavior of drug addicts.

- There is a strong need to expand the scope of research in the field of drug de-addiction to improve the effectiveness of treatment by the DDC centers providing preventive and curative services to the addicts in future and to provide evidence in policy makers that sufferers are eagerly awaiting effective preventive, curative and rehabilitative services in the state of Punjab.

\section{Contribution by Co-Authors}

The co-Authors helped to collect and analysis the data collected from various DDCs of the Punjab state to prepare and finalize the manuscript. Dr. Mitra made correspondence for various additional inputs.

\section{What this study adds to the existing knowledge}

It is very clear from the present study that at the grass root level lot of inputs are needed to over-com the worst scenario of drug addiction in Punjab. The menace of drug addiction and mush-rooming of the private DDCs are adding fuel to the already burning situation in the state.

Therefore government of Punjab and community must share the responsibility to help and support the existing DDCs with more infrastructure and skilled human resources to counter this menace of drug-addiction in Punjab to save the youth and future Generations.

\section{Reference}

01. Suwanwela C, Poshyachinda V. Drug abuse in Asia. Bull Narc. 1986 Jan-Jun;38(1-2)41-53.

[Crossref]

02. Manual on Standards of Services for the Programmes under the Scheme for Prevention of Alcohlism and Substance Drugs Abuse. Ministry of Social Justice and Empowerment, Government of India. Shastri Bhavan, New Delhi. 2001.

[Crossref]

03. Prevalence of drug abuse in America. (online accessed on 30th December 2008).

Available from: [Article] [Crossref] 
04. National survey. The extent, Pattern and Trends of Drug Abuse in India, Ministry of Social Justice and Empowerment. Govt of India. 2004.

[Crossref]

05. Sandhu RS. On behalf of Department of Social Security and Development of Women and Children. Survey of the rural households in Punjab. 2005.

Available at: [Article] [Crossref]

06. Narcotic Drugs \& psychotropic substances (NDPS) act, 1975. The Gazette of India, [Act No 61 of 1985; Act No 2 of 1989] Annexure-V. (List of import of narcotic drugs and psychotropic substances under the NDPS Act and NDPS rules). 1975.

[Crossref]

07. Drug De-Addiction Programme. Annual Report (2006-07), Ministry of Health \& FW. Govt of India. 2006;146.

[Crossref]

08. Mohan C, Dhar V, Lal B. A study of 1 deaddiction clinic at GMC (Psychiatry hospital) Jammu (J\&K). Indian J Psychiatry abstract supplement. 2004;34;23.

[Crossref]
09. DeSilva PV \& Fonseka P. Drug addicts and their behaviour related to drug addiction amoung the institutionalized addicts of the Galle District. Galle Medical Journal. September-2008; 13(1): 9-13.

[Crossref]

10. Singh B, Singh V, Vij A. Socio-demographic profile of substance abusers attending a deaddiction centre in Ghaziabad. Ind Medica. 2006;6(1)1-3.

[Crossref]

11. Kadri A, Bhagyalaxmi A, Kedia G. A study of socio-demographic profile of substance abusers attending a de-addiction centre in ahmedabad city. Indian Journal of community medicine. 2003;XXVII(2)pp-74-77.

[Crossref]

12. Saluja B, Grover S, Irpati A, Mattoo S, Basu D. Drug dependence in adolescents 1978-2003- A clinical-based observation from north India. The Indian Journal of Pediatrics. 2007; 74(5)455458.

[Crossref] 